\title{
OBSERVATIONS ON THE URINARY EXCRETION OF SULFADIAZINE
}

\author{
By OSLER L. PETERSON, ROBERT A. GOODWIN, JR., AND MAXWELL FINLAND \\ (From the Thorndike Memorial Laboratory, Second and Fourth Medical Services (Harvard), \\ Boston City Hospital, and the Department of Medicine, Harvard Medical School, Boston)
}

(Received for publication February 11, 1943)

Although the kidney is the main excretory channel for the sulfonamide drugs as well as the site of some of the most serious complications resulting from their use, the factors influencing their excretion have received less attention than they deserve. Marshall, Emerson, and Cutting (1) concluded from their studies on dogs that increasing the rate of urine flow apparently increased the renal clearance of sulfanilamide. Their finding was subsequently supported by the work of Stewart, Rourke, and Allen (2) in human subjects. On the other hand, Alyea, Daniel, and Yates (3) and later Lucas and Mitchell (4) presented data which they interpreted as showing that sulfanilamide is excreted at a constant rate, irrespective of the urine volume. Bullowa and his coworkers (5) found, in patients, that sulfapyridine is excreted at an irregular rate which is independent of the rate of urine flow. Clearance rates of the various sulfonamide derivatives has indicated considerable degrees of tubular reabsorption (1, 6 to 12 ). The clinical impression is prevalent that excretion of sulfapyridine, sulfathiazole, and sulfadiazine can be hastened by "forcing fluids," and the procedure is usually recommended in patients who are exhibiting toxic effects from these drugs. There are no adequate data, however, to support this impression.

In this paper are presented the results of attempts by various procedures to induce diuresis of drug and of urine in persons receiving sulfadiazine in ordinary therapeutic doses. An increase in the rate of excretion of drug may be of some advantage in patients who are exhibiting severe systemic reactions, such as drug rashes, fevers, or agranulocytosis. Water diuresis, on the other hand, would obviously be desirable in patients who manifest urinary tract irritation as a result of the precipitation of the drug. It was the purpose of this study to determine which of the procedures in common use most effectively produces these two results, either separately or simultaneously.

\section{MATERIALS AND METHODS}

The subjects in whom these studies were carried out were young or middle-aged men who, during convalescence from acute alcoholism, mild respiratory infections, or erysipelas, were kept in the hospital particularly for this purpose. They were all afebrile and had normal kidney function. Some of them were kept in bed and others were up and about in a small ward throughout the study. With few exceptions, several procedures were carried out in each subject. Throughout most of the studies, it was desirable to maintain a fairly constant and large fluid intake. Fluids were, therefore, given, as nearly as possible at the rate of 200 to $250 \mathrm{ml}$. per hour, day and night, throughout the study and for several days before any procedure was carried out. Urine samples were collected hourly from 7 a.m. to 7 p.m. Subjects who could not void on the hour, or in whom there was reason to believe that the bladder was not being completely emptied at each micturition, were excluded from the study.

Only the studies with sulfadiazine are being reported here, although a number of similar observations were made with sulfathiazole and sulfanilamide. Each subject received an initial dose of 4 grams of the sulfonamide, followed by 1 gram every 4 hours, day and night, throughout the period of observation. At first, blood samples were taken for sulfadiazine levels 5 or 6 times a day, but it was soon found that, after 2 or 3 days on a constant dosage, the concentrations of the drug in the blood during any given day were sufficiently constant so that only 2 or even a single sample sufficed. The chemical determinations of sulfadiazine in blood and urine were carried out by the method of Bratton and Marshall (13), using a photoelectric colorimeter.

The volume and specific gravity of each urine specimen was measured immediately after it was voided. Determinations of the $\mathrm{pH}$ of the urine were carried out with a glass electrode potentiometer, usually within a few minutes after it was collected. In a number of specimens, the observations were repeated after overnight storage in a refrigerator and no significant variations in $\mathrm{pH}$ were noted, indicating that the sulfadiazine acted as a good preservative.

The following procedures were investigated for their effect on sulfadiazine and water excretion: (1) intravenous injection of $1500 \mathrm{ml}$. of a 5 per cent solution of glucose in distilled water; (2) intravenous injections of $1500 \mathrm{ml}$. of 0.85 per cent sodium chloride solution in water; (3) ingestion of $1500 \mathrm{ml}$. or more of cold tap water; (4) intravenous injection of $100 \mathrm{ml}$. of 50 per 


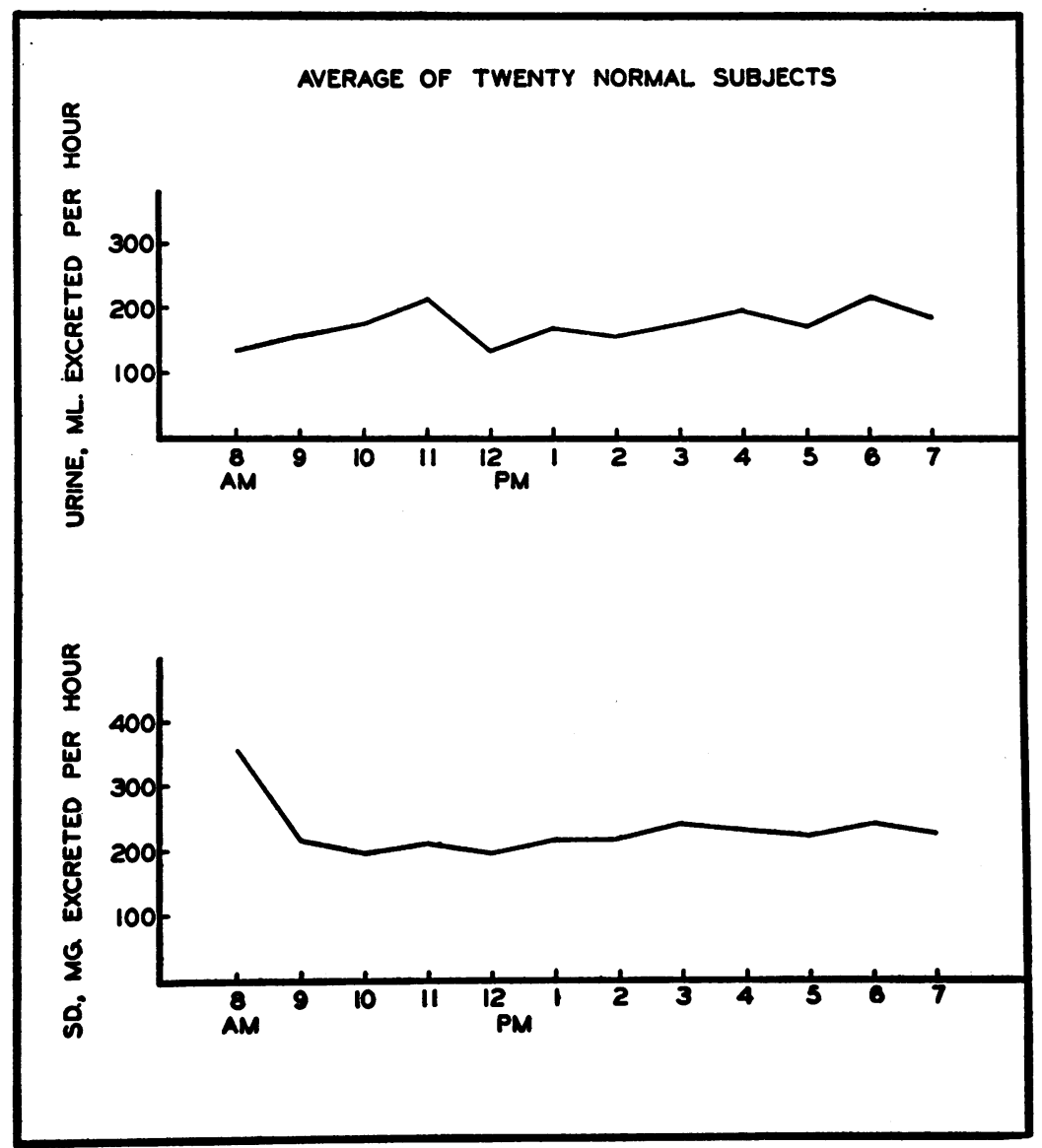

Fig. 1. Average Hourly Output of Urine and Sulfadiazine (SD) in 20 Essentially Normal Subjects During Control Periods of Constant Fluid and Drug InTAKe

cent glucose solution; (5) ingestion of 15 to 25 grams of sodium bicarbonate with a small amount of water; and (6) a few observations were also made on the effect of urea and ammonium chloride. In addition, one group of studies was made on the fate of single doses of drug in the same subject during periods of high or low fluid intake.

A single procedure was carried out at noon on a given day and urine samples were collected throughout that day. Blood samples were drawn before and at suitable intervals after the procedure. The first 3 procedures were carried out over a period of an hour. Control urine and blood samples were also collected for several days before and, usually, after each procedure was carried out. The patients were on a regular hospital diet throughout these studies. Beyond the fact that the meals were usually served at the same time each day, it was not felt necessary to control the elements of the diet for these studies (14 to 17 ).

\section{RESULTS}

Control observations. There were many variations in the amount of sulfadiazine excreted from hour to hour, throughout the day, during the control periods of constant drug intake and essentially constant fluid intake. As a rule, when an unusually small amount of the drug was excreted during one hour, there was an apparently compensatory increase in the amount excreted during the following hour. Contrariwise, a greatly increased excretion in one hour was usually followed by a decreased amount. Spontaneous variations in the volume of urine voided from hour to hour, throughout the day, were also frequent. Many of the latter variations may have been attributable, in part, to changes in diet, posture, or activity. The urine excreted during the first, and sometimes also the second, hour after the subjects awoke in the morning, usually contained more sulfadiazine than was excreted in any other hour of the day, even in those who were kept in bed.

The average hourly excretion of urine and of 
sulfadiazine during control periods in 20 essentially normal subjects is shown in Figure 1. The level of the hourly sulfadiazine excretion curve varied greatly in the different subjects but the general shape of this curve is characteristic. The hourly urine volumes, on the other hand, were very inconstant and the curves for the individual subjects varied considerably from the average curve shown in the figure.

It was noted on several occasions that when the volume of urine in any given period was very small, it contained unusually small amounts of drug. A striking example was that of one subject who, in 3 successive hours, excreted 80,16 , and $230 \mathrm{ml}$. of urine containing 172,15 , and $176 \mathrm{mgm}$. of sulfadiazine, respectively. In general, however, there did not appear to be any striking relation between the volume of urine excreted in any given hour and the amount of drug it contained. The data on this point are summarized in Table I. Most of the larger urine volumes noted in this table were obtained following ingestion or intravenous administration of large volumes of fluid.

The concentration of sulfadiazine found in the urine in any given hour's output was inversely proportional to the volume. This relation was more striking for that portion which was determined as "conjugated" drug. When, however, the hourly urine volume was $50 \mathrm{ml}$. or less, the average concentration of free drug was no greater than in volumes of 51 to $100 \mathrm{ml}$. This suggests a possible upper limit for the concentration of free sulfadiazine that can ordinarily be excreted.

The actual amount of sulfadiazine excreted per hour was low only when the average urine volume was $50 \mathrm{ml}$. or less. There was a proportionate increase in the amount of drug with hourly volumes of 51 to $100 \mathrm{ml}$. but only slight further changes with greater urine output, except when unusually large volumes ( $500 \mathrm{ml}$. or more) were passed. This was true for both the free and the conjugated portions. The percentage of the chemical that was excreted in the latter form was more or less constant, except in the low urine volumes which contained a higher proportion of conjugated drug.

Blood concentrations of sulfadiazine were fairly constant throughout each day. The variations in any one subject on any given day ranged from 0.7 to $2.5 \mathrm{mgm}$. per $100 \mathrm{ml}$, with a mean of 1.6 mgm. during the control observation. The averages of the lowest and highest values for the total blood concentrations were 8.5 and $10.1 \mathrm{mgm}$. per $100 \mathrm{ml}$., respectively. In view of the various errors inherent in the method, it would appear that spontaneous variations in the blood levels throughout the day were not great.

Excretion of sulfadiazine was definitely less during the night than during the day. There was not much difference, however, between the first half and the second half of the night. Studies in 6 subjects gave an average hourly excretion of $158 \mathrm{mgm}$. between 7 p.m. and 1 a.m., as compared with $176 \mathrm{mgm}$. between 1 a.m. and 7 a.m. The average $\mathrm{pH}$ of the urine excreted between 7 a.m. and 7 p.m. during control periods was 6.06 .

Effect of intravenous injection of $1500 \mathrm{ml}$. of 5 per cent glucose (Figure 2). Each of the 5 subjects who received such an injection had intense water diuresis during the hour of the injection and

TABLE I

Relation of urine volume to sulfadiazine excretion

\begin{tabular}{|c|c|c|c|c|c|c|c|c|}
\hline \multicolumn{2}{|c|}{$\begin{array}{l}\text { Urine volume } \\
\text { (ml. per hour) }\end{array}$} & $\begin{array}{c}15 \text { to } \\
50\end{array}$ & $\begin{array}{c}51 \text { to } \\
100\end{array}$ & $\begin{array}{l}101 \text { to } \\
200\end{array}$ & $\begin{array}{l}201 \text { to } \\
300\end{array}$ & $\begin{array}{c}301 \text { to } \\
400\end{array}$ & $\begin{array}{l}401 \text { to } \\
500\end{array}$ & $\begin{array}{c}501 \text { to } \\
1200\end{array}$ \\
\hline \multicolumn{2}{|l|}{$\begin{array}{l}\text { Number of specimens } \\
\text { Average volume (ml. per hour) }\end{array}$} & $\begin{array}{l}15 \\
34\end{array}$ & $\begin{array}{l}48 \\
77\end{array}$ & $\begin{array}{r}46 \\
153\end{array}$ & $\begin{array}{r}46 \\
252\end{array}$ & $\begin{array}{r}28 \\
352\end{array}$ & $\begin{array}{r}13 \\
452\end{array}$ & $\begin{array}{r}25 \\
711\end{array}$ \\
\hline $\begin{array}{l}\text { Average SD* concentration } \\
(\mathrm{mgm} . \text { per } 100 \mathrm{ml} .)\end{array}$ & $\begin{array}{l}\text { Free } \\
\text { Total } \\
\text { Conjugated }\end{array}$ & $\begin{array}{r}185 \\
268 \\
83\end{array}$ & $\begin{array}{r}199 \\
258 \\
59\end{array}$ & $\begin{array}{r}112 \\
143 \\
31\end{array}$ & $\begin{array}{l}78 \\
96 \\
18\end{array}$ & $\begin{array}{l}51 \\
61 \\
10\end{array}$ & $\begin{array}{r}39 \\
47 \\
8\end{array}$ & $\begin{array}{r}30 \\
37 \\
7\end{array}$ \\
\hline $\begin{array}{l}\text { Average SD excreted } \\
\quad(m g m . \text { per hour })\end{array}$ & $\begin{array}{l}\text { Free } \\
\text { Total } \\
\text { Conjugated }\end{array}$ & $\begin{array}{l}63 \\
91 \\
28\end{array}$ & $\begin{array}{r}153 \\
199 \\
46\end{array}$ & $\begin{array}{r}171 \\
219 \\
48\end{array}$ & $\begin{array}{r}197 \\
243 \\
46\end{array}$ & $\begin{array}{r}180 \\
214 \\
34\end{array}$ & $\begin{array}{r}178 \\
214 \\
36\end{array}$ & $\begin{array}{r}214 \\
265 \\
51\end{array}$ \\
\hline \multicolumn{2}{|l|}{ Per cent conjugated } & 30 & 23 & 16 & 15 & 16 & 17 & 19 \\
\hline
\end{tabular}

* SD = Sulfadiazine. 


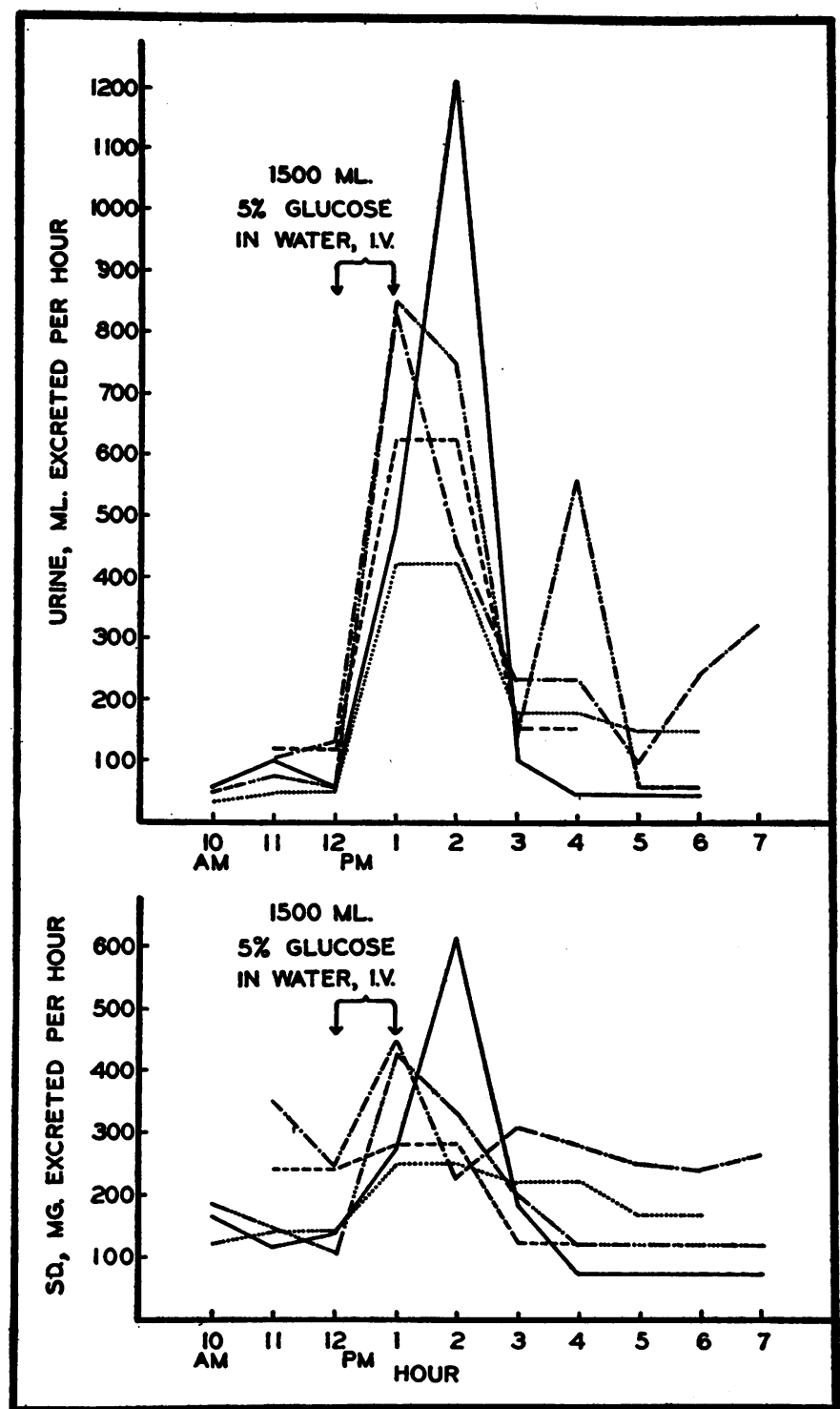

Fig. 2. Hourly Drug and Urine Excretion in 5 Subjects Who Received an Intravenous Injection of 1500 ML. OF 5 PER cent Glucose in Distilled Water, from Noon to 1 P.M.

In this and in the subsequent figures, the corresponding data for urine volume and drug output in the same subject are indicated by the same type of lines.

during the following hour. Accompanying the increased urine output, there was a sharp, but relatively smaller, increase in the hourly excretion of sulfadiazine. The concentration of drug in the urine was, therefore, less during the period of diuresis than it was before or after. The average amount of sulfadiazine excreted by these 5 subjects, in the 3 hours preceding the veniclysis, was
$469 \mathrm{mgm}$.; in the following 3 hours, the average output was $875 \mathrm{mgm}$., - an increase of 86 per cent. There were wide variations in the response of the different subjects, and this proved to be the case with each of the procedures used. One subject excreted between 104 and $182 \mathrm{mgm}$. of sulfadiazine each hour before the injection and 422 mgm. during the hour of the injection (in 850 
ml. of urine). In another subject, the drug excretion increased only from 240 to $270 \mathrm{mgm}$., although the corresponding urine volumes increased from $120 \mathrm{ml}$. before to $620 \mathrm{ml}$. after the injection was begun. The 2 subjects who put out the largest amounts of urine in the hours before the veniclysis, responded to the glucose injection with a smaller increase in sulfadiazine excretion than did those with the small initial urine outputs. This was to be expected from what has been noted previously concerning the small amounts of drug contained in the very small hourly urine volumes.

In one of the subjects, similar studies were carried out at different times with sulfanilamide and with sulfathiazole. The effect of the intravenous injection of $1500 \mathrm{ml}$. of 5 per cent glucose on the excretion of these drugs, in this subject, was the same as with sulfadiazine. In 3 subjects receiving sulfadiazine, 10 per cent glucose gave results similar to those obtained with the 5 per cent solution. Blood sugar and quantitative urinary sugar de- terminations were made in one subject. The blood sugar rose from 107 before to $298 \mathrm{mgm}$. per $100 \mathrm{ml}$. immediately after the end of the injection and returned to $104 \mathrm{mgm}$. per $100 \mathrm{ml}$. one hour later. Approximately 20 grams of sugar were recovered from the urine in the first 2 hours and 80 per cent of this amount was excreted in the first hour. In this subject, the maximum drug excretion did not coincide with the maximum glycosuria.

Effect of intravenous injection of $1500 \mathrm{ml}$. of physiological saline (Figure 3 ). The results of this procedure, which was carried out in 5 subjects, were quite different from those obtained with 5 per cent glucose. The urine output was increased at a slower rate but persisted over a longer period after the saline injection. In 2 of the subjects, the increased urine flow continued for the remainder of the day ( 7 hours). During the first 3 hours after the saline was given, the average urine output was increased 135 per cent

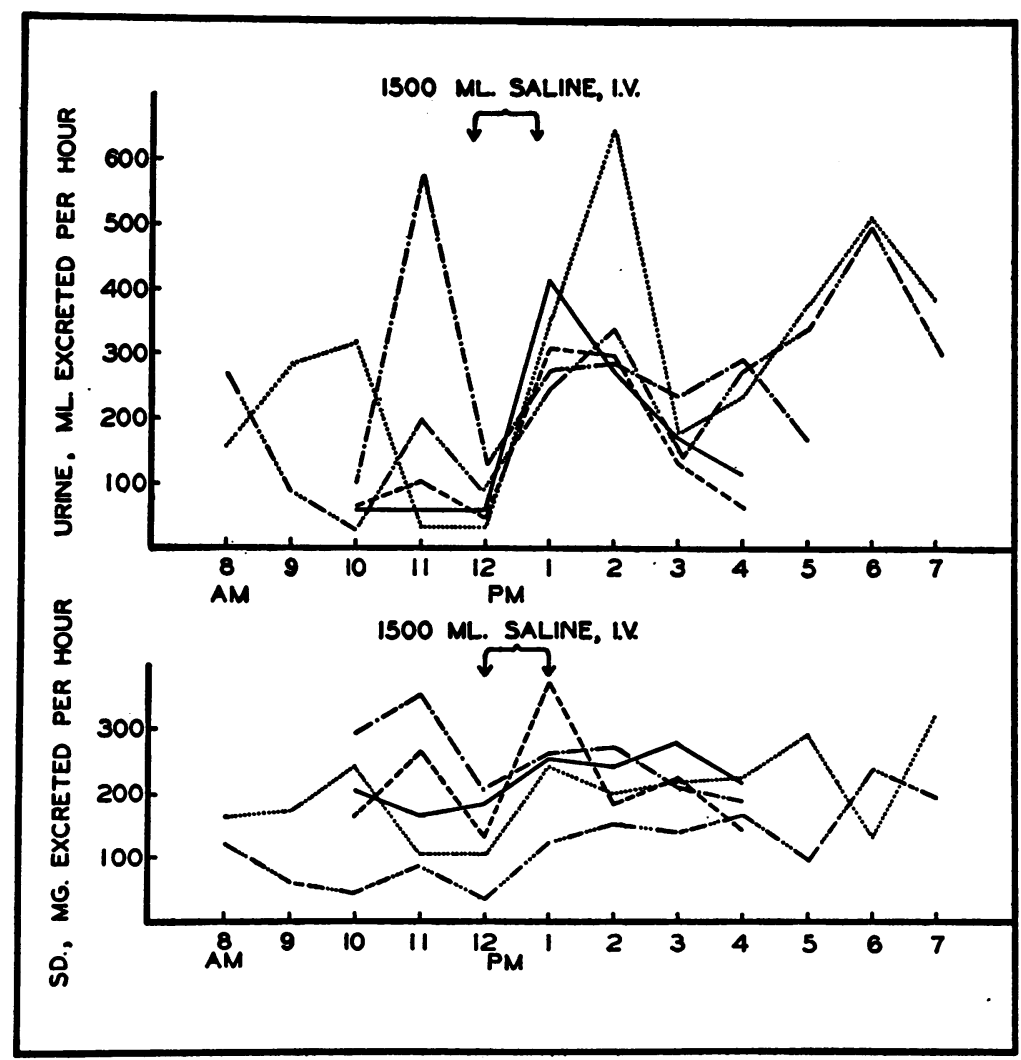

Fig. 3. Hourly Drug and Urine Excretion in 5 Subjects Who Received 1500 ml. of Physiological Saline Intravenously 


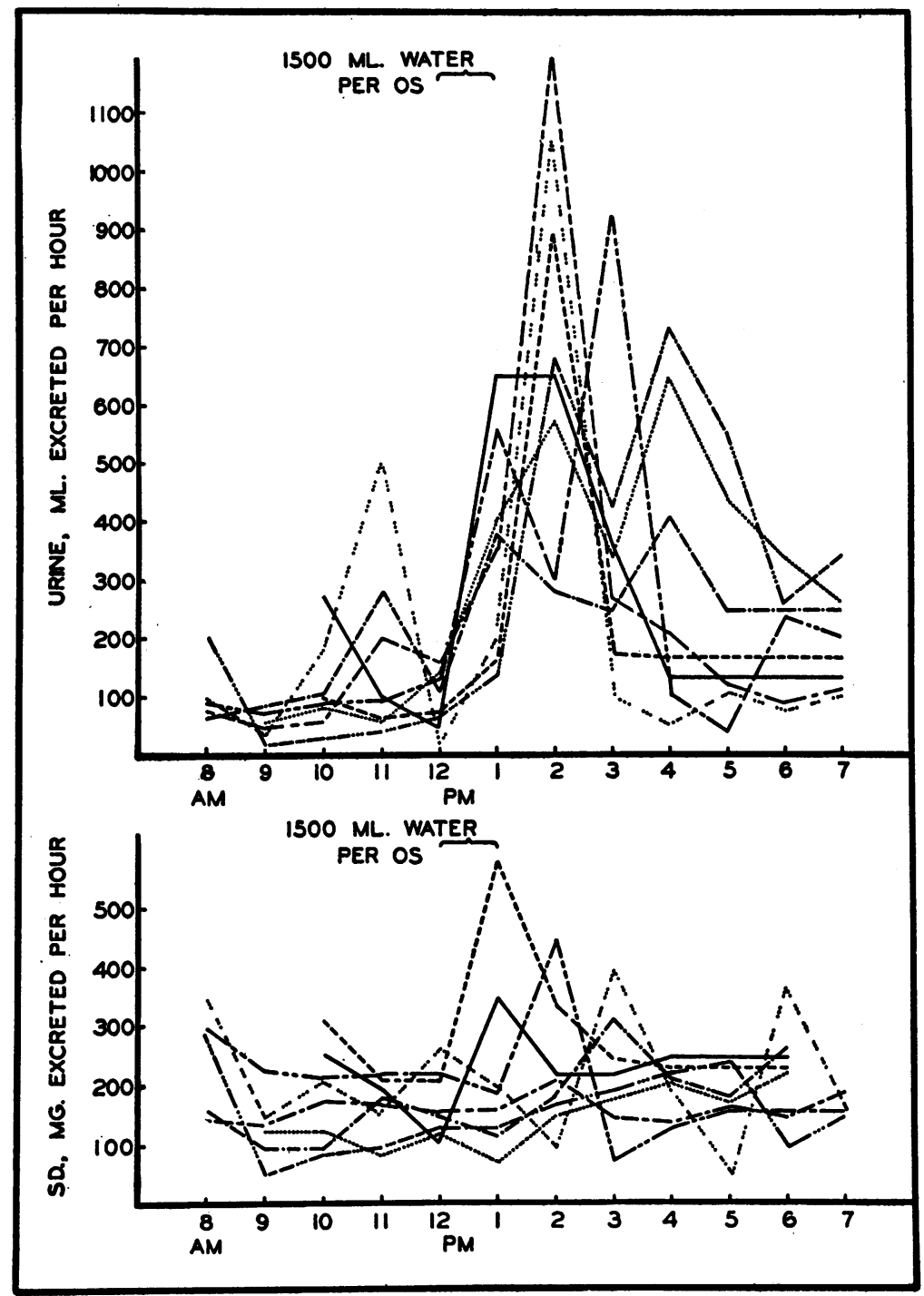

Fig. 4. Hourly Sulfadiazine and Urine Output in 8 Subjects Who INGESTED 1500 ML. OR MORE OF WATER

over the preceding 3 hours. During the same period, the average sulfadiazine excretion was increased only 37 per cent.

Effect of large amounts of water taken orally (Figure 4). One and a half liters of water (or more when tolerated) were given by mouth to 8 subjects over a period of an hour. A good diuresis resulted in every instance. The maximum urine output occurred in the hour after the entire amount of water had been consumed. In 3 subjects, the increased urine flow continued for another 2 or 3 hours.

The excretion of sulfadiazine varied. In 3 in- dividuals, there was a definite and marked increase in output of the drug. In 2 of the latter, the increase occurred during the hour when the water was being taken but their urine volume did not increase significantly until the next hour, at which time the sulfadiazine excretion had almost returned to the prediuretic level. The third subject had a relatively low rate of urine flow before the water was given. His urine volume rose from $150 \mathrm{ml}$. the hour before to $1200 \mathrm{ml}$. in the second hour after the water ingestion, and the sulfadiazine excretion for the corresponding periods rose from 200 to $440 \mathrm{mgm}$. During the next hour, his 
urine output dropped to $250 \mathrm{ml}$. and he excreted only $77 \mathrm{mgm}$. of drug. This decreased sulfadiazine excretion continued for 4 hours and completely compensated for the additional drug carried out during the period of maximum diuresis.

For all 8 subjects, the average urine output in the 3 hours after the ingestion of the water was 308 per cent greater than in the preceding 3 hours. The excretion of sulfadiazine during the corresponding period was increased only 26 per cent. In general, therefore, the large volumes of fluid given by mouth were relatively ineffective in increasing the total amount of sulfadiazine excreted but were highly effective in reducing the concentration of drug in the urine.

Effect of hypertonic glucose given intravenously. Five subjects were given $100 \mathrm{ml}$. of 50 per cent glucose, intravenously, at noon, taking 10 to 15 minutes for its administration. The hourly urine and sulfadiazine excretions are charted in Figure 5. In 2 of the subjects, there was an unusually large urine output and in a third, a large drug output sometime prior to the injection. Glucose appeared in the urine in large amounts for 1 to 4 hours after the injection, giving an orange to red reduction of Benedict's solution. The spe-

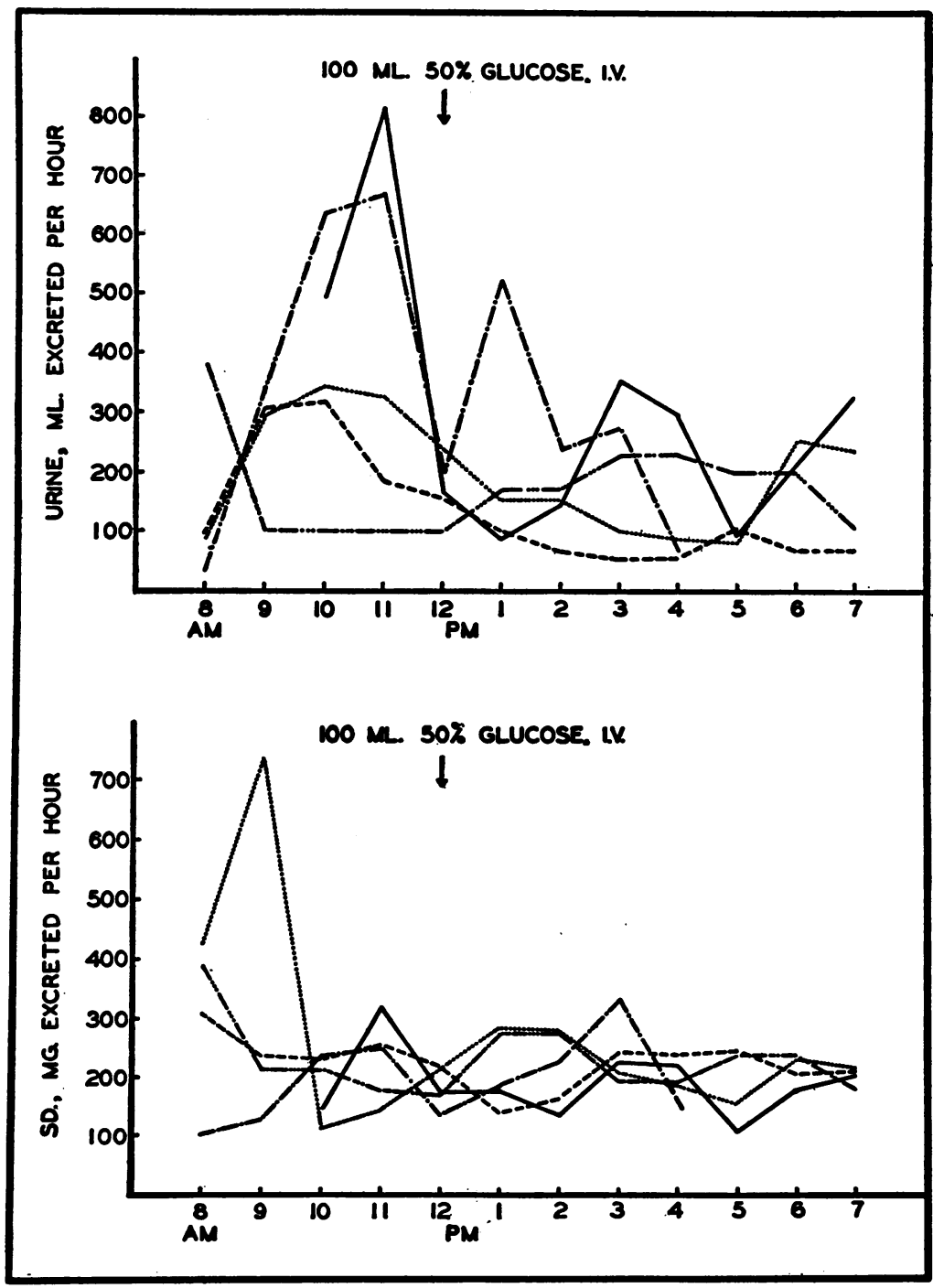

Fig. 5. Hourly Sulfadiazine and Urine Excretion in 5 SUbjects Given 100 ML. OF 50 PER CENT Glucose INTRAVENOUSLY 


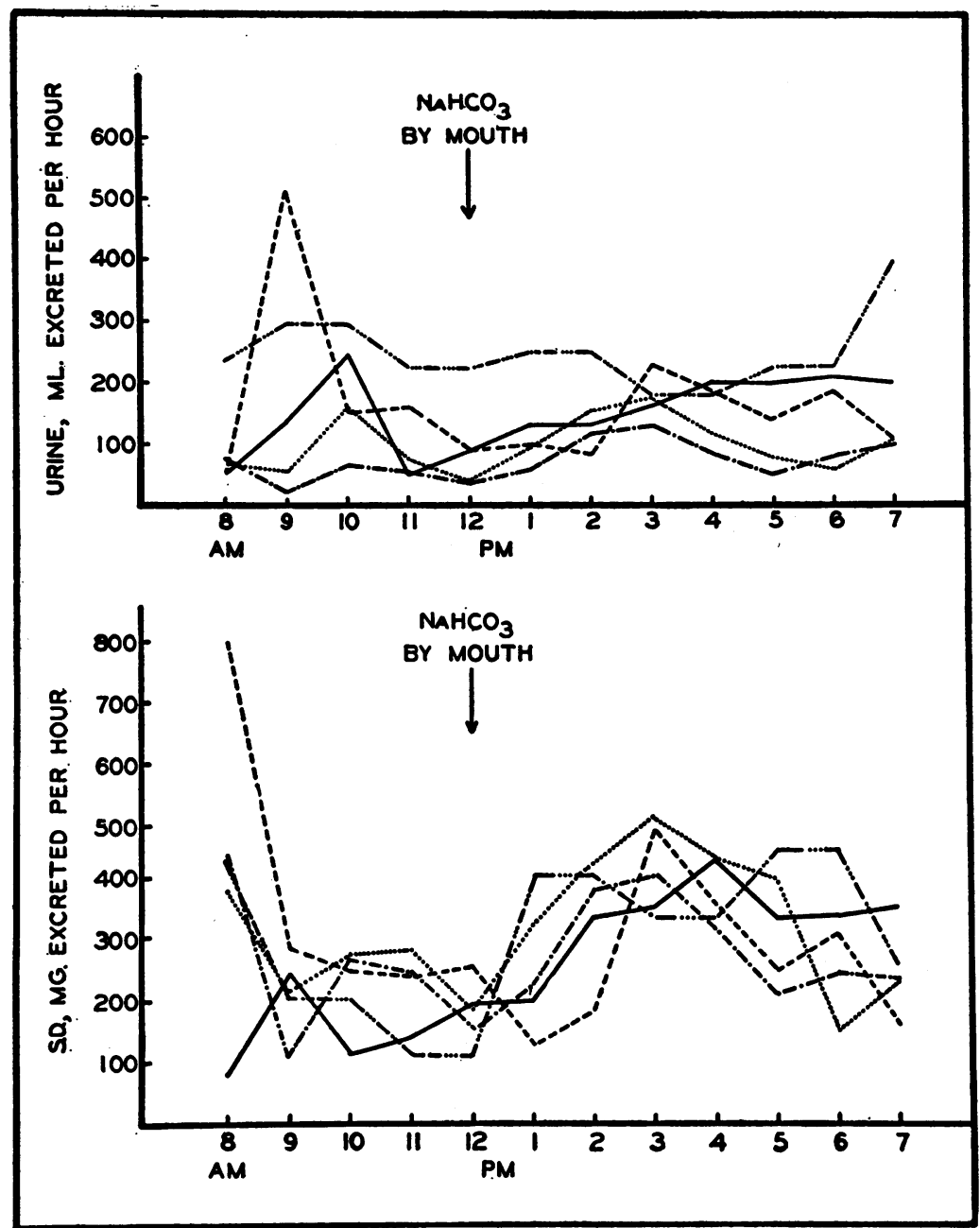

Fig. 6. Hourly Urine and Sulfadiazine Output Before and After the Oral Administration of 15 to 25 grams of Sodium Bicarbonate

cific gravity of the sugar-containing urine specimens averaged 1.015 , as compared with an average of 1.007 for those collected before the glucose was given. The urine volume was not regularly increased. The average amount of sulfadiazine excreted during the 3-hour period following the glucose administration was only 11 per cent greater than the average amount of drug recovered during the preceding 3 hours.

Effect of urea alone or in addition to intravenous glucose. It was noted by Curtis and Sobin (18) that the solubility of acetylsulfapyridine and of acetylsulfathiazole in urine increased roughly with the specific gravity and that this may be related to the greater urea content of the urine. It was of interest, therefore, to observe the effect of urea on sulfadiazine excretion. Two subjects were given 50 grams of urea each, by mouth. The specific gravity of the hourly urine specimen was 1.005 to 1.010 in the hours prior to its administration and 1.016 to 1.020 for the next 3 hours. The hourly excretion of urine and of sulfadiazine was not affected appreciably. Two other subjects were each given $\mathbf{5 0}$ grams of urea by mouth and an intravenous injection of $100 \mathrm{ml}$. of 50 per cent glucose at the same time. Although the specific gravity of the urine was markedly increased following these procedures, there was no striking diuresis of water or of sulfadiazine.

Effect of alkali. Preliminary observations on the effect of alkalinization of the urine on the 
amount of sulfadiazine excreted were made with sodium lactate. One subject was given 5 grams and another 10 grams of this compound as onesixth molar solution, intravenously. The $\mathrm{pH}$ of the urine increased somewhat following this procedure and a moderate increase in the sulfadiazine output resulted. Because of the greater ease in administration, sodium bicarbonate was used orally in the subsequent studies, 5 subjects being given doses of from 15 to 25 grams. The hourly urine volumes and drug excretion in these 5 subjects are shown in Figure 6.

The $\mathrm{pH}$ of the urine in these 5 subjects ranged between 5.4 and 6.6 and averaged 6.06 before the soda was given; it rose only slightly during the first hour but increased to an average of 8.0 during the second hour and even higher in some instances during the following hours. Along with this increase in $\mathrm{pH}$, there was a marked increase in sulfadiazine excretion which reached a peak during the third hour and declined thereafter. In 2 cases, there was still a high drug output as long as 7 hours after the sodium bicarbonate was given. The average amount of drug excreted for each of the 4 hours before the bicarbonate administration was $208 \mathrm{mgm}$., as compared with an hourly average excretion of $340 \mathrm{mgm}$. during the subsequent 5 hours. The volume of urine excreted remained essentially constant throughout the entire period, although an additional $250 \mathrm{ml}$. of water were given to facilitate the ingestion of the alkali. The average hourly volume of urine passed was $147 \mathrm{ml}$. during the 4 hours preceding and $158 \mathrm{ml}$. during the 5 hours after the alkali was given.

Blood samples were taken in each subject before and 4 hours after the soda was given. The concentration of sulfadiazine in the latter samples was from 0.8 to $3.0 \mathrm{mgm}$. per $100 \mathrm{ml}$. less than in the earlier samples. The average decrease in the blood level was 14 per cent.

In order to contrast the effect of an acid urine excretion, 2 of the last 5 subjects were given 3 and 4 grams, respectively, of ammonium chloride orally on the day after they received the alkali. The $\mathrm{pH}$ of the urine fell from 7.3 and 7.5 to $\mathbf{5 . 5}$ and 5.9 , respectively. Coincidentally, the hourly sulfadiazine excretion decreased from over 200 $\mathrm{mgm}$. to less than $150 \mathrm{mgm}$. in both instances.

Two subjects were each given increasing doses of sodium bicarbonate orally on 2 successive days. One of them received 10 grams on one day. This resulted in a moderate increase in sulfadiazine output from about $200 \mathrm{mgm}$. per hour to a maximum of $400 \mathrm{mgm}$. per hour when the $\mathrm{pH}$ of the urine rose to 7.9. On the next day, he was given 20 grams and had a further increase in output of the drug, reaching a maximum in the third hour after this dose when $516 \mathrm{mgm}$. were excreted. The urine $\mathrm{pH}$ at this time was 8.3. A very similar result was obtained in the second subject who received 15 and 20 gram doses of bicarbonate of soda on successive days. The blood sulfadiazine concentration in these 2 subjects dropped 9 and 20 per cent, respectively. ${ }^{1}$

The average hourly excretion of sulfadiazine at different $\mathrm{pH}$ levels is shown in Table II. The amount of sulfadiazine excreted per hour increased steadily with increase in the alkalinity of the urine. The additional amount put out, however, consisted entirely of the "free" component, the amount of the conjugated drug excreted at different $\mathrm{pH}$ levels remaining essentially constant. The percentage of sulfadiazine determined as conjugated drug was, therefore, greater in the acid urines. The volume of urine did not show the same relation to $\mathrm{pH}$ as did the amount of drug excreted. The highest hourly urine volumes were those having $\mathrm{pH}$ values between 6.1 and 7.0. The concentration of sulfadiazine in the urine was greatest in the most alkaline samples and lowest in those with a $\mathrm{pH}$ value between 6.1 and 7.0.

\footnotetext{
1 The danger of using this procedure for increasing sulfonamide excretion in patients who have a disturbed water metabolism was strikingly illustrated in a case of portal cirrhosis of the liver with a plasma protein level of 5.08 grams per $100 \mathrm{ml}$. This patient, who was receiving sulfadiazine therapy for a mild infection, was given 10 and 15 gram doses of sodium bicarbonate on successive days. Following the first dose, he responded with a definite increase in sulfadiazine output. After the second dose, there was an increase in the amount of the drug excreted but there was a decrease in the volume of urine. Three hours after the second dose of bicarbonate, the patient developed hematuria and ureteral colic which was quickly relieved by forcing fluids by mouth. The combination of increased sodium and water intake, however, precipitated the development of marked edema and ascites (19) which had previously been absent. It is of interest that the hematuria and colic occurred in spite of the known increase in solubility of sulfonamides in alkaline urines $(11,18,20)$.
} 
TABLE II

Relation of urinary $p H$ to sulfadiazine excretion

\begin{tabular}{|c|c|c|c|c|c|c|}
\hline \multicolumn{2}{|l|}{$\mathrm{pH}$ of urine } & 5.0 or less & 5.1 to 6.0 & 6.1 to 7.0 & 7.1 to 8.0 & 8.1 to 9.0 \\
\hline \multicolumn{2}{|l|}{$\begin{array}{l}\text { Number of specimens } \\
\text { Average volume (ml.per hour) }\end{array}$} & $\begin{array}{r}9 \\
116\end{array}$ & $\begin{array}{l}104 \\
158\end{array}$ & $\begin{array}{r}84 \\
222\end{array}$ & $\begin{array}{r}66 \\
164\end{array}$ & $\begin{array}{r}23 \\
148\end{array}$ \\
\hline $\begin{array}{l}\text { Average } \mathrm{SD}^{*} \text { concentration } \\
(\mathrm{mgm} . \text { per } 100 \mathrm{ml} .)\end{array}$ & $\begin{array}{l}\text { Free } \\
\text { Total } \\
\text { Conjugated }\end{array}$ & $\begin{array}{r}107 \\
147 \\
40\end{array}$ & $\begin{array}{r}90 \\
122 \\
32\end{array}$ & $\begin{array}{r}77 \\
101 \\
24\end{array}$ & $\begin{array}{r}143 \\
170 \\
27\end{array}$ & $\begin{array}{r}177 \\
212 \\
35\end{array}$ \\
\hline $\begin{array}{l}\text { Average SD excreted } \\
\text { (mgm. per hour) }\end{array}$ & $\begin{array}{l}\text { Free } \\
\text { Total } \\
\text { Conjugated }\end{array}$ & $\begin{array}{r}124 \\
170 \\
46\end{array}$ & $\begin{array}{r}142 \\
193 \\
51\end{array}$ & $\begin{array}{r}171 \\
225 \\
54\end{array}$ & $\begin{array}{r}235 \\
278 \\
43\end{array}$ & $\begin{array}{r}259 \\
311 \\
52\end{array}$ \\
\hline \multicolumn{2}{|l|}{ Per cent conjugated } & 27 & 26 & 24 & 15 & 16 \\
\hline
\end{tabular}

The highest and lowest $\mathrm{pH}$ values were obtained after administration of sodium bicarbonate and ammonium chloride, respectively.

$* \mathrm{SD}=$ Sulfadiazine.

The effect of alkalinity on sulfadiazine excretion is seen to be quite striking if one computes the output of drug on a daily basis. At $\mathrm{pH}$ levels between 6.1 and 7.0, the amount of drug excreted daily would approximate the intake. With acid urines having a $\mathrm{pH}$ of 5.0 or less, only about 4 grams would be eliminated each day, while with urines at $\mathrm{pH}$ values above 8.0, the daily output of drug would be about 7.5 grams.

Effect of prolonged administration of sulfadiazine. There was an opportunity to make observations of interest in connection with the present studies in 2 patients who received sulfadiazine continuously, one for 9 months and the other for 7 months. Both eventually developed some impairment of renal function which returned to normal after the drug was stopped. The first patient was tested early in the course of treatment and responded to an intravenous injection of 5 per cent glucose with a marked increase in both water and sulfadiazine excretion. When the procedure was repeated before the drug therapy was stopped, he responded with a slow and moderate increase in urine output but no increase in the amount of sulfadiazine excreted. The second patient was being treated for actinomycosis and attempts were made to maintain blood levels of "free" drug at $15 \mathrm{mgm}$. per $100 \mathrm{ml}$. or higher. This required 9 grams daily at first but later could be achieved with decreasing amounts until only 2 grams daily were needed during the seventh month. During the fifth month of therapy, this patient responded to intravenous injection of $1500 \mathrm{ml}$. of 5 (and later 10) per cent glucose solution by slowly excreting the excess fluid, but no increase in sulfadiazine excretion resulted.

Fate of single doses of sulfadiazine during periods of high and of low fluid intake. In the preceding studies, the effects of different procedures were observed in subjects in whom both drug and fluid intakes were maintained at a constant rate. An attempt was also made to compare the fate of a single dose of sulfadiazine, first during a period of high fluid intake and then during a period when the fluids were limited (or vice versa). In order to avoid differences in absorption, each dose was given intravenously, as the sodium salt, in $50 \mathrm{ml}$. of physiological saline. Studies in one subject are presented as illustrative of the results and of the difficulties involved.

The subject weighed 86 kilograms and had not received any sulfonamide in several weeks. First, he was put on a daily fluid intake of 4500 to $5100 \mathrm{ml}$., distributed more or less evenly throughout the day. On the fourth day of the regime, he was given 6.9 grams of sodium sulfadiazine intravenously (0.08 gram per kilogram of body weight) and maintained on the same fluid intake (about 5 liters a day) for another 4 days. Blood was taken for sulfadiazine determinations at suitable intervals after the injection. All the urine voided was also collected and assayed for its drug content. One week later, the subject was put on a daily fluid intake of 1800 to $2000 \mathrm{ml}$. per day. After 8 days on this regime, the same amount of sodium sulfadiazine was given and the observations on the blood concentrations and urinary excretion of the drug were repeated while the subject was being kept on an intake of 2 liters of fluid a day.

Immediately after the second injection, the subject complained of a transient slight dizziness and a mild pressure sensation in the head. About 15 minutes later he felt dull pain in the costo-vertebral regions and in the flanks 


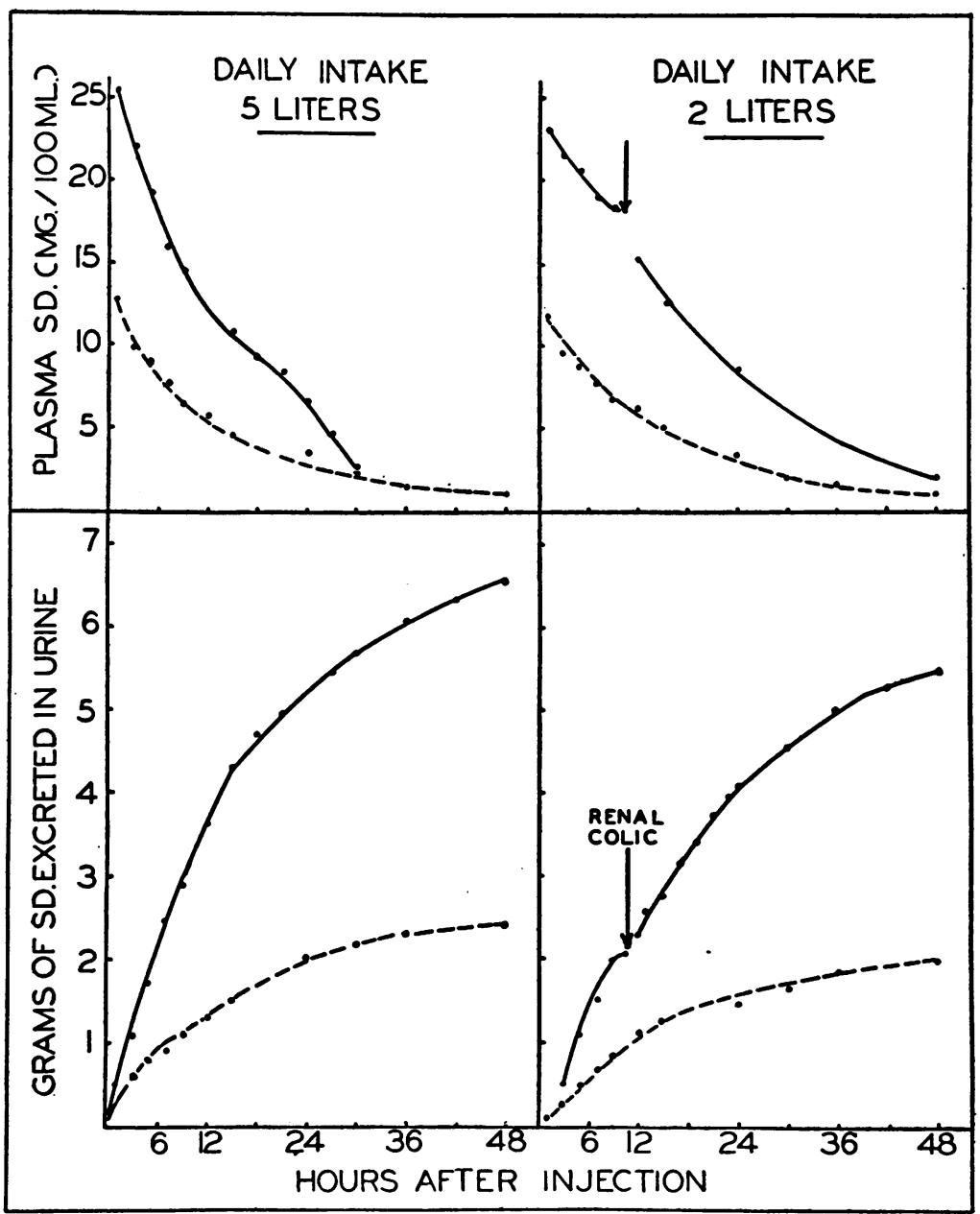

Fig. 7. Plasma Sulfadiazine Levels and Cumulative Urinary Sulfadiazine Excretion During Periods of High (5 liters) and Low (2 liters) DaIly Fluid Intake

The solid lines represent the results obtained after 6.9 grams and the broken lines after 3.0 grams of sodium sulfadiazine, given intravenously. The values are for total sulfadiazine. At the point marked "renal colic," the subject was given an intravenous infusion of $1500 \mathrm{ml}$. of 5 per cent glucose and fluids were forced throughout the next day.

but did not complain of it. This persisted for 9 hours after which he began to have severe costo-vertebral and abdominal distress and headache with nausea but without vomiting. All the urines voided during the first 16 hours after this injection contained a few red blood cells and those voided up to 24 hours also contained a few sulfadiazine crystals in the sediment. Because of this complication, the subject was given an intravenous infusion of $1500 \mathrm{ml}$. of 5 per cent glucose and fluids were forced by mouth with complete and rapid relief. One week later, the studies were repeated without incident, this time giving 3 gram doses of sodium sulfadiazine.
The results are shown graphically in Figure 7. After the 3 gram doses, the blood levels were about the same on both the high and the low fluid regimes. The urinary excretion of the drug, however, occurred at a somewhat more rapid rate while on the high fluid intake. The greatest difference occurred during the first 3 hours, during which almost two and a half times as much drug was excreted on the high fluid intake as on the lower fluid regime. From then on, however, the rates of drug excretion were almost the same. 

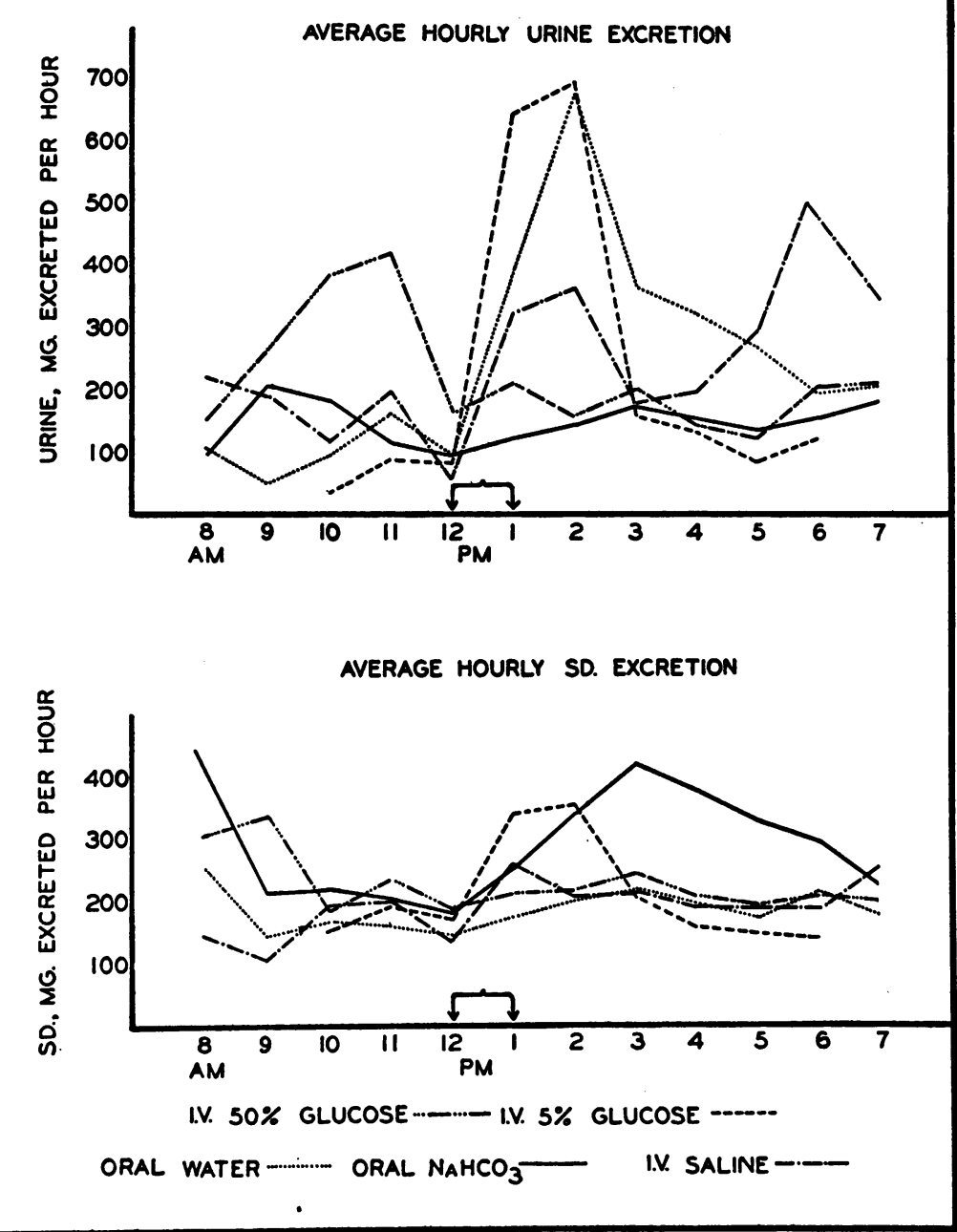

Fig. 8. Average Hourly Urine and Sulfadiazine Excretion as Influenced by Various Procedures

The points on each curve represent the averages for the values at the corresponding time as shown in Figures 2 to 6 . The values are for "total" sulfadiazine.

After the larger doses of sulfadiazine (see Figure 7), there was obvious retention of the drug in the blood for the first few hours of the period of low fluid intake. This may have resulted directly from renal irritation. After fluids were forced, the curve of drug output was similar to that obtained on the high fluid regime.

The average values for the hourly excretion of urine and of sulfadiazine, as they were influenced by the various procedures tested, are shown graphically in Figure 8.

\section{DISCUSSION}

The relation of the volume of urine to the quantity of sulfadiazine excreted, as shown in Table I, raises interesting points. It seems probable that any urine flow in excess of $50 \mathrm{ml}$. per hour is adequate in a normal individual for the excretion of the amounts of drug ordinarily employed for therapy and those used here, namely 1 gram every 4 hours. With a urine flow of less than $50 \mathrm{ml}$. per hour, the excretion of sulfadiazine is definitely retarded. With very large urine vol- 
umes, up to $1200 \mathrm{ml}$. per hour, sulfadiazine excretion is increased somewhat irregularly, but the increment is probably of no clinical importance, particularly since the maintenance of such a large urine output is impractical except for short periods. The administration of 50 per cent glucose intravenously, or of large amounts of urea by mouth, seemed to have little or no effect on the sulfadiazine excretion in normal subjects. It is possible, however, that in edematous patients, these procedures may be useful in mobilizing fluid and thus improving the excretion of the chemical indirectly.

The results of the studies presented here suggest a more rational employment of the various procedures during the ordinary therapeutic uses of the sulfonamide drugs. For example, in the management of the rashes, fevers, or blood disorders resulting from this form of treatment, it is desirable to eliminate the drug from the body as completely and as rapidly as possible. The use of bicarbonate of soda in amounts sufficient to insure a highly alkaline urine should be most effective for this purpose. If one desires to maintain high blood levels, it may be useful to keep the patient on a regime which insures a good output of an acid urine. This may require the administration of ammonium chloride or similar acid-producing substances in certain cases. Such a procedure may, in some instances, prove safer than increasing the dose of the drug orally, or giving supplemental doses parenterally, or limiting the fluid intake.

When renal complications such as oliguria or hematuria occur, the indication is for increasing the urine output. Intravenous injection of large amounts of 5 or 10 per cent glucose solution (in distilled water) produces this effect most promptly and is, therefore, the treatment of choice for this purpose. The ingestion of large volumes of water, if well tolerated, is also useful and does not increase the drug output as much as does the isotonic glucose infusion.

The intravenous administration of saline deserves mention because it is used so widely. This procedure may be very useful in improving hydration and in restoring electrolytes, but it does not produce an increase in urine or drug output rapidly or in proportion to the amount of fluid given. In patients who are extremely ill, and particularly in post-operative cases, an unusually high incidence of hematuria, oliguria, renal colic, and anuria has, in our experience, been associated with the repeated intravenous administration of the sodium salts of sulfathiazole and sulfadiazine in saline. Obviously, if the saline is needed to correct dehydration, other more diuretic fluids such as isotonic or 10 per cent glucose in distilled water should be given in addition, in order to assure an adequate volume of urine.

The state of hydration is obviously important as indicated by the results obtained in the study of the fate of single doses of sulfadiazine during periods of high and low fluid intake. More of the sulfadiazine was excreted when the patient was on a large fluid intake than when on the restricted regime. With the latter, there is great danger of renal complications, particularly if large intravenous doses of drug are given. This should be borne in mind, particularly in initiating therapy in extremely ill patients who are very likely to be dehydrated from a combination of vomiting, sweating, and restricted fluid intake. In such cases, the intravenous route is often used for drug administration, either by necessity or by choice. It is essential, in such instances, to introduce a moderate amount of fluid first and delay the injections of drug until the dehydration has been largely corrected.

\section{SUMMARY AND CONCLUSIONS}

Data have been presented on the effect of a number of commonly used procedures on the excretion of urine and drug in subjects who were taking regular doses of sulfadiazine.

The greatest and most prolonged increase in excretion of sulfadiazine resulted from the administration of alkali (sodium bicarbonate) in amounts sufficient to insure a highly alkaline urine.

A decrease in the concentration of the drug in the urine was obtained most rapidly by the intravenous injection of a large volume of 5 or 10 per cent glucose solution in distilled water. The ingestion of water in large amounts produced a similar result somewhat less rapidly. The intravenous infusion of physiological saline gave a less marked reduction in the concentration of drug in the urine and the effect was more delayed. Only the first of these 3 procedures was accompanied by a large increase in drug output. 
Care should be taken to insure proper hydration of a patient before undertaking the intravenous injection of large amounts of sulfadiazine.

The authors are indebted to Dr. F. H. L. Taylor and Dr. Alexander W. Winkler for helpful suggestions. The chemical determinations were made by Alice N. Ballou and Dorothy L. Souza.

\section{BIBLIOGRAPHY}

1. Marshall, E. K., Jr., Emerson, K., Jr., and Cutting, W. C., The renal excretion of sulfanilamide. J. Pharmacol. and Exper. Therap., 1937, 61, 191.

2. Stewart, J. D., Rourke, G. M., and Allen, J. G., Excretion of sulfanilamide. J. A. M. A., 1938, 110, 1885.

3. Alyea, E. P., Daniel, W. E., and Yates, A., Sulfanilamide and disulfanilamide concentrations in the blood and urine. J. Urol., 1939, 41, 14.

4. Lucas, C. C., and Mitchell, D. R., A biochemical study of patients on sulphanilamide therapy. Canad. M. A. J., 1939, 40, 27.

5. Bullowa, J. G. M., Ratish, H. D., Davidson, A., and Lebair, C., Administration of sulfapyridine and its congeners in pneumonias. New York State J. Med., 1940 40, 1450.

6. Marshall, E. K., and Litchfield, J. T., Some aspects of the pharmacology of sulfapyridine. J. Pharmacol. and Exper. Therap., 1939, 67, 454.

7. Reinhold, J. G., Flippin, H. F., and Schwartz, L., Observations on the pharmacology and toxicology of sulfathiazole in man. Am. J. M. Sc., 1940, 199, 393.

8. Reinhold, J. G., Flippin, H. F., Schwartz, L., and Domm, A. H., The absorption, distribution and excretion of 2-sulfanilamido pyrimidine (sulfapyrimidine, sulfadiazine) in man. Am. J. M. Sc., 1941, 201, 106.

9. Strauss, E., Lowell, F. C., Taylor, F. H. L., and Finland, M., Observations on the absorption, ex- cretion and distribution of sulfanilamide, sulfapyridine, sulfathiazole, and sulfamethylthiazole. Ann. Int. Med., 1941, 14, 1360.

10. Peterson, O. L., Strauss, E., Taylor, F. H. L., and Finland, M., Absorption, excretion and distribution of sulfadiazine (2-sulfanilamido-pyrimidine). Am. J. M. Sc., 1941, 201, 357.

11. Schwartz, L., Flippin, H. F., Reinhold, J. G., and Domm, A. H., The effect of alkali on crystalluria from sulfathiazole and sulfadiazine. J. A. M. A., 1941, 117, 514.

12. Frisk, A. R., The renal clearance of various sulfanilamide derivatives and the distribution of free and conjugated compound between corpuscles and plasma in man. Acta. med. Scandinav., 1941, 106, 404.

13. Bratton, A. C., and Marshall, E. K., Jr., A new coupling component for sulfanilamide determination. J. Biol. Chem., 1939, 128, 537.

14. Smith, M. I., Lillie, R. D., and Stohlman, E. F., The influence of dietary protein on the toxicity of sulfanilamide. Pub. Health Rep., 1941, 56, 24.

15. Stohlman, E. F., and Smith, M. I., Influence of fasting on retention and conjugation of sulfanilamide in rabbits. Proc. Soc. Exper. Biol. and Med., 1942, 49, 432.

16. Kapnick, I., Lyons, C., and Stewart, J. D., Influence of diet on sulfanilamide toxicity. J. Pharmacol. and Exper. Therap., 1942, 74, 284.

17. Peterson, O. L., and Finland, M., The effect of food and alkali on the absorption and excretion of sulfonamide drugs after oral and duodenal administration. Am. J. M. Sc., 1942, 204, 581.

18. Curtis, A. C., and Sobin, S. S., Solubility studies on acetylsulfapyridine. J. A. M. A., 1941, 116, 2529.

19. Strauss, M. B., Observations on the etiology of the toxemias of pregnancy. II. Production of acute exacerbation of toxemia by sodium salts in pregnant women with hypoproteinemia. Am. J. M. Sc., 1937, 194, 772.

20. Sunderman, F. W., and Pepper, D. S., Sulfathiazole in blood and urine. Am. J. M. Sc., 1940, 200, 790. 